\title{
PENGARUH CAIRAN ALUMINIZING TERHADAP KEKERASAN KAWAT BAJA
}

\author{
Dwi Purwanto $\mathbf{N}^{1}$, Dody Prayitno ${ }^{2}$ \\ 1,2 Jurusan Teknik Mesin, Fakultas Teknologi Industri Universitas Trisakti \\ Jl. Kyai Tapa No.1, Grogol, RT.6/RW.16, Tomang, Grogol petamburan, Jakarta Barat.11440 \\ E-mail : dwi.purwanto.n@gmail.com ${ }^{1}$, diktirisetgrup@gmail.com²
}

\begin{abstract}
Abstrak
Tali baja terbuat dari beberapa kawat baja yang dipilin membentuk strand. Beberapa strand tersebut dipilin mengelilingi core untuk membentuk sebuah tali baja. Salah satu contoh pemakaian nya untuk menahan beban yang berat seperti jembatan gantung. Tali baja ini terdiri dari beberapa bagian yakni, kawat baja, core, dan wire strand. Dalam upaya meningkatkan kekuatan kawat baja, terbuka peluang meningkatkan kekuatan kawat baja dengan metode aluminizing. Penelitian ini bertujuan untuk mengetahui pengaruh aluminizing terhadap kawat baja tersebut, dalam hal ini digunakan tembaga dan timah putih yang dicampurkan dengan cairan aluminium. Sampel diperoleh dari penguraian tali baja, selanjut nya sampel tersebut direndam di dalam cairan pada suhu $700^{\circ} \mathrm{C}$ selama \pm 3 menit. Cairan terdiri atas a) Al-Cu, b) Al-Cu-Sn dengan Sn konsentrasi 10\%, c) Al-Cu-Sn dengan Sn konsentrasi 20\%, d) AlSn. Sampel kawat kemudian diangkat dan didinginkan pada suhu ruang, setelah itu dilakukan pengujian kekerasan mikro dan pengukuran kekasaran serta ketebalannya. Pengujian kemudian dianalisis dengan menggunakan SPSS karena dapat melakukan analisis yang sama terhadap pengamatan varian yang berbeda secara sekaligus, yang terbukti bahwa terjadi peningkatan kekerasan pada lapisan intermetalik.
\end{abstract}

Kata kunci: Aluminizing, Kawat baja, Kekerasan, Intermetalik.

\begin{abstract}
Wire rope is made from several steel wires a combined form a strand, a couple of strands twisted around the core to form a steel rope. One example of its usage is on the bridge to provide support for a heavy load. The steel wire is composed of several parts that is, steel wire, core and wire strand. Increasing the hardness of steel wire have the impact, the hardness of the steel wire. In an effort to improve the hardness of steel wire, there are opportunities to increase the hardness of steel wire with aluminizing method. The aim of this research is to find out the hardness of Wire in aluminizing process with alloys $\mathrm{Al}-\mathrm{Cu}-\mathrm{Sn}$. Moreover to the research also aims to focus on the addition of Sn element in $\mathrm{Al}-\mathrm{Cu}$ liquid. The methodology research was preceded by spliting wires from the wire rope. After that cut the wire into the sample wire. Then soak the wire into $\mathrm{Al}-\mathrm{Cu}-\mathrm{Sn}$ liquid at a temperature of $700^{\circ} \mathrm{C}$ for \pm 3 minutes. Elements of Sn which contained in the composition of $\mathrm{Al}-\mathrm{Cu}-\mathrm{Sn}$ vary from $0 \%, 10 \%$ and $20 \%$, while for CU's component is $10 \%$ and the rest of is $\mathrm{Al}$, and the latter only elements of $\mathrm{Al}$ - Sn, without adding $\mathrm{Cu}$ element. Wire samples were then take away and cooled at room temperature, then test the wire by using micro hardness test, the test data was analyzed with Anova and finally made a conclusion. The results of this of this research showed that for the violence that occurs in the intermetallic layer shows the increase in value of hardness obtained on steel wire.
\end{abstract}

Keywords: Aluminizing, Wire rope, Hardness, Intermetalic

\section{PENDAHULUAN}

Kawat baja merupakan komponen penting untuk peralatan konstruksi guna mengangkat, menahan dan menggantung beban material. Sehingga kawat baja menjadi bagian komponen penting yang membutuhkan perhitungan kekokohan dan penanganan yang cermat agar aman digunakan. Kekokohan kawat baja dapat dievaluasi dengan mengukur kekuatan dan kekerasan pada kawat baja (Kholis, 2014).

\section{TINJAUAN PUSTAKA}

\section{Kawat Baja}

Tali kawat baja adalah elemen penting dalam menahan, mengangkat dan memindahkan beban. Asumsi tali kawat baja sebagai mesin dapat diterima karena memiliki beberapa bagian bergerak yang menahan beban dan secara dinamis mendistribusikannya untuk dapat melakukan pekerjaan. Salah satu kelebihannya adalah mampu menahan beban yang berat. Tali kawat baja dapat menahan beban dari 
berbagai arah yang tidak mampu dilakukan oleh alat angkat lain (Kholis, 2014).

Beberapa kawat baja (steel wire) dipintal sehingga didapat suatu jalinan yang disebut strand, kemudian beberapa strand dijalin pula pada serat inti (core) sehingga membentuk suatu jalinan yang disebut tali kawat baja (Muin, 1995).

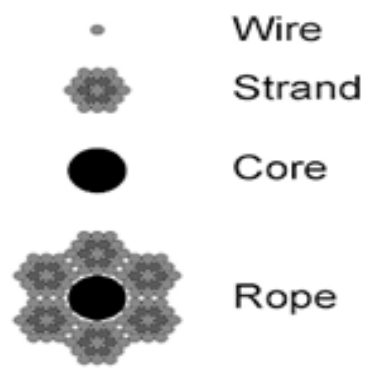

Gambar 1. Bagian kawat baja

Hal-hal yang menyebabkan menurunnya tingkat kekerasan pada kawat baja adalah tegangan akibat beban yang terlalu berat, keausan dan kelelahan akibat penipisan pada permukaannya. Hal tersebut diharapkan dapat berkurang melalui proses aluminizing, yaitu dengan cara mencelupkan kawat baja ke dalam bak yang berisi lelehan logam pelapis. Proses tersebut akan membentuk ikatan metalurgi yang baik karena terjadinya proses interface alloying (Sudiashri et al, 2012).

\section{Aluminizing}

Bahan paduan aluminium banyak dikembangkan dalam dunia industri untuk melapisi permukaan logam karena memiliki potensi tahan korosi dan ketahanan terhadap oksidasi temperatur tinggi. Aluminium merupakan bahan yang memiliki sifat mekanik yang relatif baik, ulet dan kekerasan yang baik apabila dipadukan untuk melipisi logam.

Tercelupnya sampel didalam cairan aluminum akan memberikan kesempatan bagi aluminium untuk berdifusi kedalam sampel baja. Difusi ini menghasilkan senyawa $\mathrm{fe}_{\mathrm{n}} \mathrm{Al}_{\mathrm{m}}$ yang dikenal dengan nama lapisan intermetalik. Difusi berlangsung dengan cara mencelupkan kedalam paduan secara cepat dan menghasilkan lapisan yang terbentuk dalam waktu \pm 3 menit. Terwujudnya lapisan intermetalik pada seluruh permukaan akan menyebabkan ketahanan korosi dan kekerasan nya meningkat (Rey, P, D., \& Prayitno, D., 2015).

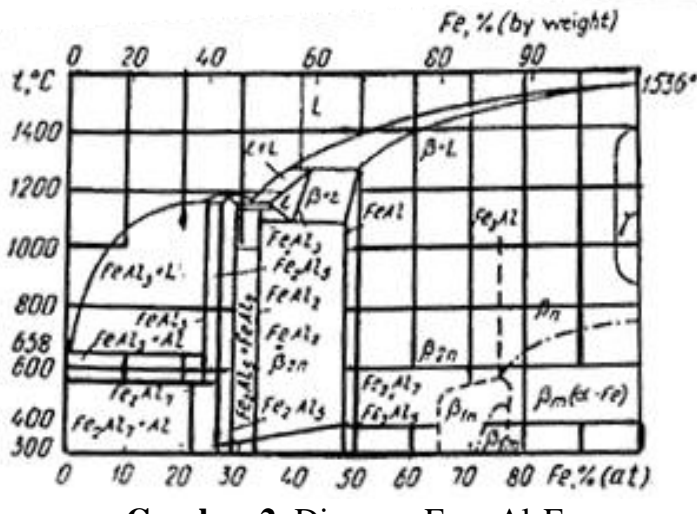

Gambar 2. Diagram Fasa Al-Fe

\section{Mekanisme Melekatnya Aluminium pada Baja (die soldering)}

Peristiwa die soldering umumnya lebih sering disebabkan oleh tingginya temperatur dan kecepatan $\mathrm{Al}$ cair masuk ke kawat baja. Temperatur logam cair dan permukaan kawat baja memegang peranan penting dalam menyebabkan terjadinya die soldering. Tingginya logam cair akan menurunkan kekerasan dan ketahanan aus sehingga kawat baja akan mudah tererosi. Temperatur yang tinggi baik untuk pertumbuhan fasa intermetalik karena laju difusi atom-atom besi ( $\mathrm{Fe})$ dan $\mathrm{Al}$ meningkat. Tingginya temperatur juga akan merusak lapisan pelumas sehingga menurunkan kemampuannya untuk mencegah die soldering. Itulah sebabnya tingginya temperatur logam cair mempermudah terjadinya die soldering, terdiri:

- Erosi permukaan logam

- $\quad$ Pitting pada permukaan logam

- Pembentukan senyawa Fe-Al

- Pembentukan fasa pyramid dari fasa intermetalik

- Pelekatan fasa Al ke intermetalik

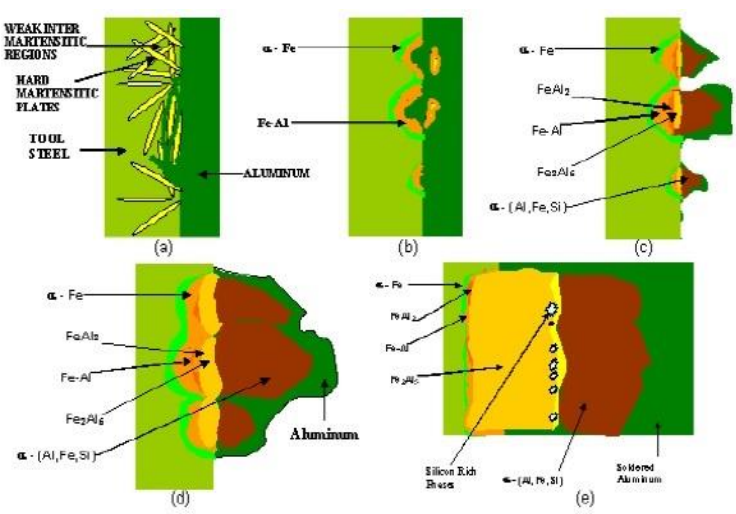

Gambar 3. Ilustrasi mekanisme die soldering.

Proses alumunizing yang mudah secara praktek adalah metode pelapisan Al celup panas (Hot Dip Alumunizing). Tahapan prosesnya diawali dengan membersihkan permukaan sampel baja dari kotoran.Dilanjutkan dengan pencelupan didalam cairan alumunium untuk beberapa lama. Kemudian sampel ditarik keluar dari cairan alumunium dan terakhir 
didinginkan di udara terbuka. Tercelupnya sampel di dalam cairan alumunium akan memberikan kesempatan bagi alumunium untuk berdifusi ke dalam sampel baja. Difusi ini menghasilkan senyawa logam $\mathrm{Fe}_{\mathrm{n}} \mathrm{Al}_{\mathrm{m}}$ yang dikenal sebagai lapisan intermetalik. Difusi berlangsung sangat cepat dan menghasilkan lapisan dengan ketebalan 0.02-0.10 mm yang terbentuk dalam waktu 115 menit. Terwujudnya lapisan intermetalik pada seluruh permukaan akan menyebabkan ketahanan korosi meningkat.

\section{Mekanisme Terjadinya Kekerasan}

Tingginya temperatur logam cair akan menurunkan kekerasan dan ketahanan aus sehingga kawat baja akan mudah tererosi. Temperatur yang tinggi baik untuk pertumbuhan fasa intermetalik karena laju difusi atomatom besi $(\mathrm{Fe})$ dan $\mathrm{Al}$ meningkat. Al bereaksi dengan permukaan butir yang longgar, dan pada permukaan terbentuk lubang yang memiliki kandungan fasa biner FeAl. Pembentukan lapisan senyawa biner ini disebabkan oleh reaksi dari setiap fasa dengan mencair nya $\mathrm{Al}$ secara terus menerus dan difusi Fe keluar dari permukaan baja. Pada paduan $\mathrm{Fe}-\mathrm{Al}$ adalah hasil dari pelarutan padat atom pada kisi-kisi kristal matrik. Pelarutan padat dilakukan untuk menambah kekuatan suatu material. Atom yang terlarut memiliki diameter atom yang berbeda dengan diameter atom matrik sehingga akan menyebabkan peregangan elastik diantara atom matriks sehingga akan menyebabkan peningkatan modulus elastik dimedan antar kisi dengan atom yang terlarut. Atom yang terlarutakan terdifusi kedalam atom matriks sehingga akan menghasilkan pelarutan padat.

\section{Pelapisan dengan Metode Pencelupan (Hot Dipping)}

Hot dipping adalah pelapisan logam dengan cara mencelupkan pada sebuah material yang terlebih dahulu dilebur dari bentuk padat menjadi cair pada sebuah pot atau tangki, menggunakan energi dari gas pembakaran atau menggunakan energi alternatif seperti panas listrik. Titik lebur yang digunakan pada pelapisan material ini adalah biasanya beberapa ratus derajat celcius (tidak melebihi $1000^{\circ} \mathrm{C}$ ). Chamberlain (1991), dalam metode hot dipping ini, struktur material yang akan dilapisi dicelupkan ke dalam bak berisi lelehan logam pelapis. Antara logam pelapis dan logam yang dilindungi terbentuk ikatan metalurgi yang baik karena terjadinya perpaduan proses antarmuka (interface alloying). Pengaturan tebal lapisan dalam proses ini sulit, lapisan cenderung tidak merata, yaitu tebal pada permukaan sebelah bawah tetapi tipis pada permukaan sebelah atas. Meskipun demikian, seluruh permukaan yang terkena lelehan logam itu akan terlapisi. Proses hot dipping terbatas untuk logam-logam yang memiliki titik lebur rendah, misalnya; timah, seng dan aluminium.

Bahan panduan alumunium banyak dikembangkan dalam dunia industri untuk melapisi permukaan logam karena memiliki potensi tahan korosi dan ketahanan terhadap oksidasi temperatur tinggi. Alumunium merupakan bahan yang memiliki sifat mekanik yang relative baik, ulet dan kekerasan yang baik apabila dipadukan untuk melapisi logam.Alumunium memiliki suhu lebur $660^{\circ} \mathrm{C}$ dan ferrous sebesar $1539^{\circ} \mathrm{C}$.Walaupun suhu lebur berbeda, namun berdasarkan fasa $\mathrm{Fe}-\mathrm{Al}$ pada gambar, ferrous dapat dipadukan dengan alumunium menjadi intermetalik FeAl melalui proses alumunizing (Prayitno, Dody dan Triyono, 2010)

\section{Pengujian Kekerasan Vickers}

Uji kekerasan Vickers menggunakan penumbuk piramida intan yang dasarnya berbentuk bujur sangkar. Besarnya sudut antara permukaan pyramida yang saling berhadapan adalah $136^{\circ}$. Sudut ini dipilih karena nilai tersebut mendekati sebagian besar nilai perbandingan yang diinginkan antara diameter lekukan dan diameter bola penumbuk pada uji kekerasan brinell. Angka kekerasan piramida intan (DPH), atau angka kekerasan Vickers (VHN atau VPH), didefinisikan sebagai beban dibagi luas permukaan lekukan. Pada prakteknya luas ini dihitung dari pengukuran mikroskopik panjang diagonal jejak.

\section{Pengujian Ketebalan}

Pengukuran ketebalan ini dimaksudkan untuk mengetahui efek almunizing terhadap ketebalan sampel. Pengukuran ketebalan ini menggunakan alat ukur mikrometer sekrup.

\section{Pengujian Kekasaran Permukaan}

Permukaan adalah batas yang memisahkan benda padat dengan sekelilingnya. Karakteristik permukaan memegang peranan penting dalam perancangan komponen mesin/peralatam. Banyak hal dimana permukaan dinyatakan misalnya gesekan, keausan, pelumasan, tahanan kelelahan, perekatan dua atau lebih komponen-komponen mesin, dll. Orang membuat berbagai parameter guna menandai atau mengidentifikasi konfigurasi suatu permukaan. Parameter harus terukur (bisa terukur dengan besaran atau unit tertentu), yang mungkin harus dilakukan dengan memakai alat ukur khusus yang dirancang untuk keperluan tersebut (Bimbing Atedi, Djoko Agsutono, 2010).

\section{Pengujian Struktur Mikro (Metalografi)}

Uji struktur mikro yang diterapkan pada penelitian ini adalah menggunakan foto mikro dengan pembesaran 500x.

\section{METODOLOGI PENELITIAN}

Proses dimulai dengan menyiapkan tali kawat baja kemudian dilakukan pemisahan sehingga menjadi kawat baja yang terdiri dari 5 kawat, setiap kawat memiliki panjang $6 \mathrm{~cm}$ dengan diameter $0.5 \mathrm{~mm}$. Sampel kawat baja kemudian dilakukan proses pemanasan pada suhu sekitar $700^{\circ} \mathrm{C}$ selama \pm 3 menit, yang pertama dilakukan aluminizing (hot dip) dengan cara dicelup dan direndam dalam cairan paduan $\mathrm{Al}-\mathrm{Cu} 10 \%$ selama \pm 3 menit pada suhu $700^{\circ} \mathrm{C}$, pada percobaan kedua dilakukan proses dengan variasi paduan $\mathrm{Al}-\mathrm{Cu} 10 \%-\mathrm{Sn} 10 \%$ selama 3 menit pada suhu $700^{\circ} \mathrm{C}$, pada percobaan yang ketiga dilakukan proses dengan variasi $\mathrm{Al}-\mathrm{Cu} 10 \%-\mathrm{Sn} 20 \%$ 
selama \pm 3 menit pada suhu $700^{\circ} \mathrm{C}$, pada percobaan yang ke empat dilakukan proses dengan variasi Al-Sn10\% selama \pm 3 menit pada suhu $700^{\circ} \mathrm{C}$, kemudian keempat sampel kawat didinginkan pada suhu ruangan. Selanjutnya, sampel kawat dipisahkan untuk dilakukan uji kekerasan, ketebalan, kekasaran dan pengamatan metalography. Kemudian hasil dianalisa untuk dibuatkan kesimpulan penelitian.

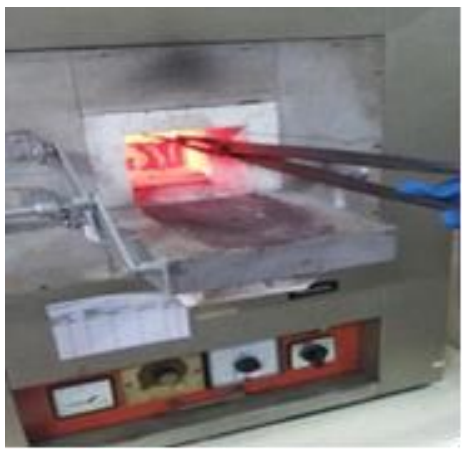

Gambar 4. Proses Almunizing (hot dip)

Perhitungan Persentasi Berat pada paduan Al-Cu-Sn:

1. Variasi paduan $\mathrm{Al}+\mathrm{Cu} 10 \%=160 \mathrm{gr} \mathrm{Al}+10 \mathrm{gr} \mathrm{Cu}$

2. Variasi paduan $\mathrm{Al}+\mathrm{Cu} 10 \%+\mathrm{Sn} 10 \%=142 \mathrm{gr} \mathrm{Al}+$ $18 \mathrm{gr} \mathrm{Cu}+18 \mathrm{gr} \mathrm{Sn}$

3. Variasi paduan $\mathrm{Al}+\mathrm{Cu} 10 \%+\mathrm{Sn} 20 \%=124 \mathrm{gr} \mathrm{Al}+$ $18 \mathrm{gr} \mathrm{Cu}+36 \mathrm{gr} \mathrm{Sn}$

4. Variasi paduan $\mathrm{Al}+\mathrm{Sn} 10 \%=160 \mathrm{gr} \mathrm{Al}+10 \mathrm{gr} \mathrm{Sn}$

\section{HASIL DAN PEMBAHASAN}

Tabel 1. Rerata Nilai Kekasaran Pada Kawat Baja

\begin{tabular}{|c|l|c|}
\hline No & \multicolumn{1}{|c|}{ Paduan } & $\begin{array}{c}\text { Rerata nilai } \\
\text { kekasaran }(\mu \mathrm{m})\end{array}$ \\
\hline 1 & $\mathrm{Al}-\mathrm{Cu} 10 \%$ & 2,838 \\
\hline 2 & $\mathrm{Al}-\mathrm{Cu} 10 \%-\mathrm{Sn} 10 \%$ & 3,496 \\
\hline 3 & $\mathrm{Al}-\mathrm{Cu} 10 \%-\mathrm{Sn} 20 \%$ & 3,732 \\
\hline 4 & $\mathrm{Al}-\mathrm{Sn} 10 \%$ & 2,113 \\
\hline
\end{tabular}

Nilai kekasaran yang tertinggi pada paduan Al-Cu10\%Sn20\% dan yang terendah pada paduan Al-Sn10\%. Penambahan Sn pada paduan Al-Cu dapat meningkatkan nilai kekasaran, namun penggantian unsur $\mathrm{Cu}(\mathrm{Al}-\mathrm{Cu})$ dengan unsur $\mathrm{Sn}(\mathrm{Al}-\mathrm{Sn})$ menyebabkan penurunan nilai kekasaran.

Tabel 2. Rerata Nilai Ketebalan Pada Kawat Baja

\begin{tabular}{|c|l|c|}
\hline No & \multicolumn{1}{|c|}{ Paduan } & $\begin{array}{c}\text { Rerata nilai } \\
\text { ketebalan }(\mathrm{mm})\end{array}$ \\
\hline 1 & $\mathrm{Al}-\mathrm{Cu} 10 \%$ & 0,166 \\
\hline 2 & $\mathrm{Al}-\mathrm{Cu} 10 \%-\mathrm{Sn} 10 \%$ & 0,128 \\
\hline 3 & $\mathrm{Al}-\mathrm{Cu} 10 \%-\mathrm{Sn} 20 \%$ & 0,104 \\
\hline 4 & $\mathrm{Al}-\mathrm{Sn} 10 \%$ & 0,054 \\
\hline
\end{tabular}

Nilai ketebalan yang tertinggi pada paduan $\mathrm{Al}-\mathrm{Cu} 10 \%$ dan yang terendah pada paduan $\mathrm{Al}-\mathrm{Sn} 10 \%$. Penambahan $\mathrm{Sn}$ pada paduan $\mathrm{Al}-\mathrm{Cu}$ dapat meningkatkan nilai ketebalan, namun penggantian unsur $\mathrm{Cu}(\mathrm{Al}-\mathrm{Cu})$ dengan unsur $\mathrm{Sn}$ (Al-Sn) menyebabkan penurunan nilai ketebalan.

Tabel 3. Rerata Nilai Kekerasan Pada Lapisan Intermetalik

\begin{tabular}{|c|l|c|}
\hline No & \multicolumn{1}{|c|}{ Paduan } & $\begin{array}{c}\text { Rerata nilai } \\
\text { kekerasan } \\
\left(\mathrm{Kg} / \mathrm{mm}^{2}\right)\end{array}$ \\
\hline 1 & $\mathrm{Al}-\mathrm{Cu} 10 \%$ & 274 \\
\hline 2 & $\mathrm{Al}-\mathrm{Cu} 10 \%-\mathrm{Sn} 10 \%$ & 572 \\
\hline 3 & $\mathrm{Al}-\mathrm{Cu} 10 \%-\mathrm{Sn} 20 \%$ & 724 \\
\hline 4 & $\mathrm{Al}-\mathrm{Sn} 10 \%$ & 824 \\
\hline
\end{tabular}

Nilai kekerasan lapisan intermetalik yang tertinggi pada paduan Al-Sn10\% dan yang terendah pada paduan Al$\mathrm{Cu} 10 \%$. Penambahan $\mathrm{Sn}$ pada paduan $\mathrm{Al}-\mathrm{Cu}$ serta penggantian unsur $\mathrm{Cu}$ (Al-Cu) dengan unsur $\mathrm{Sn}$ (Al-Sn) dapat meningkatkan nilai kekerasan pada lapisan intermetalik

Tabel 4. Rerata Nilai Kekerasan pada daerah Base Metal

\begin{tabular}{|c|l|c|}
\hline No & \multicolumn{1}{|c|}{ Paduan } & $\begin{array}{c}\text { Rerata nilai } \\
\text { kekerasan } \\
\left(\mathrm{Kg} / \mathrm{mm}^{2}\right)\end{array}$ \\
\hline 1 & $\mathrm{Al}-\mathrm{Cu} 10 \%$ & 282,2 \\
\hline 2 & $\mathrm{Al}-\mathrm{Cu} 10 \%-\mathrm{Sn} 10 \%$ & 269,2 \\
\hline 3 & $\mathrm{Al}-\mathrm{Cu} 10 \%-\mathrm{Sn} 20 \%$ & 259,8 \\
\hline 4 & Al-Sn10\% & 260 \\
\hline 5 & Initial sample & 543,4 \\
\hline
\end{tabular}

Nilai kekerasan pada lapisan base metal yang tertinggi pada sampel inisial dan yang terendah pada paduan Al$\mathrm{Cu} 10 \%-\mathrm{Sn} 20 \%$. Dengan penambahan Sn pada paduan Al$\mathrm{Cu}$ dapat mengurangi nilai kekerasan pada base metal.

\section{Hasil Struktur mikro}

Pada Tabel 5 dijelaskan mengenai gambar struktur mikro pada kawat baja. Gambar tersebut memperlihatkan lokasi pengambilan nilai kekerasan pada base metal yang dilingkari warna merah. Nilai kekerasan untuk Initial sampel lebih keras sebesar $543 \mathrm{~kg} / \mathrm{mm}^{2}$, dibanding dengan menggunakan paduan $\mathrm{Al}$ dengan nilai rata-rata sebesar $265 \mathrm{~kg} / \mathrm{mm}^{2}$. Hal ini disebabkan karena kawat baja dicelupkan pada suhu $700^{\circ} \mathrm{C}$, sehingga terjadi perubahan struktur mikro pada base metal. Karena dengan pemanasan sampai suhu $700^{\circ} \mathrm{C}$ terjadi rekristalisasi, dimana butir logam pada base metal yang dicelupkan cairan aluminizing menjadi lebih besar. Dengan terjadinya butir logam yang membesar, nilai kekerasan pada paduan $\mathrm{Al}$ menurun. 
Tabel 5. Struktur mikro pada Base Metal.

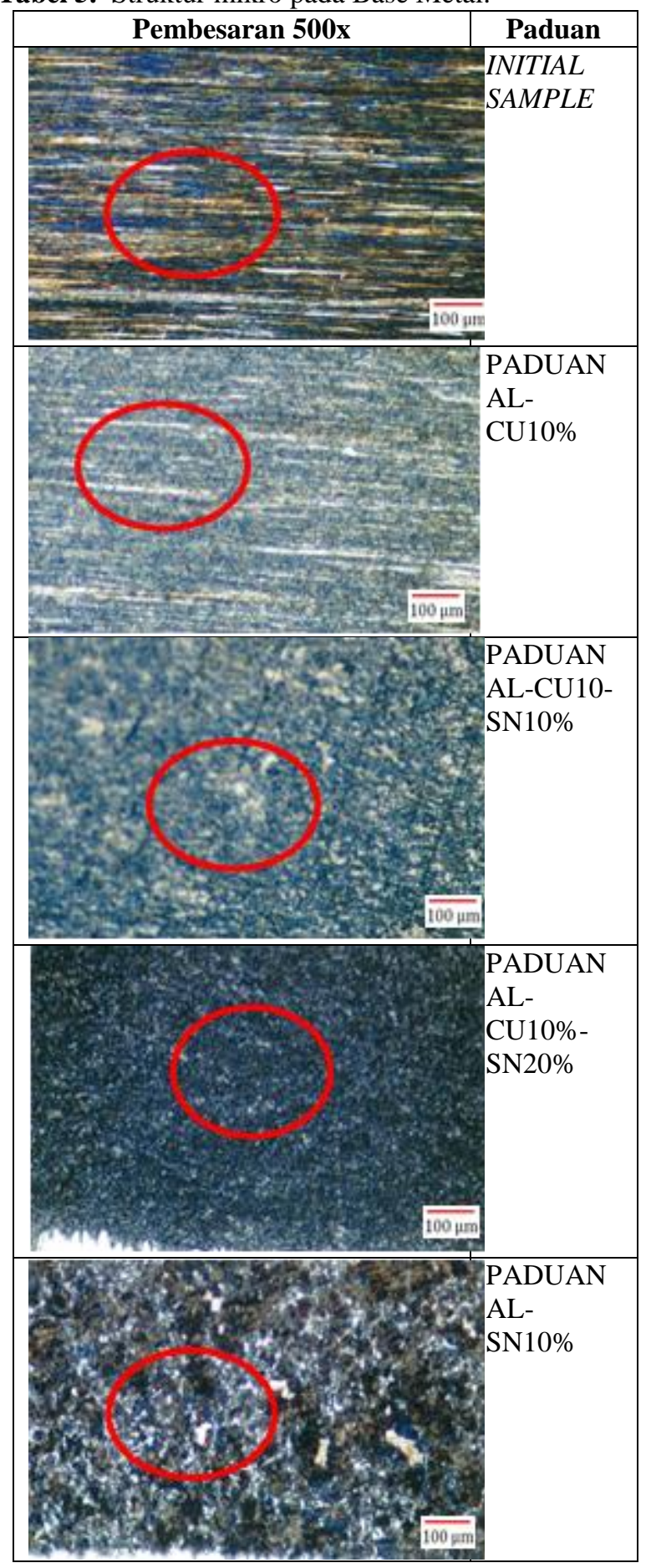

\section{Hasil Analisis Data Menggunakan SPSS}

\section{- Kekasaran}

Analisis data kekasaran paduan kawat baja dilakukan dengan uji Kruskal Wallis dikarenakan sebaran varians yang tidak homogen. Nilai yang didapatkan $\mathrm{p}=0,005$ maka dapat disimpulkan bahwa terdapat perbedaan kekasaran antara ke 4 variasi paduan.

\section{- Ketebalan}

Analisis data ketebalan paduan kawat baja dilakukan dengan uji Kruskal Wallis dikarenakan sebaran data yang tidak normal. Nilai yang didapatkan $\mathrm{p}=0.012$ maka dapat disimpulkan bahwa terdapat perbedaan ketebalan antara ke 4 variasi paduan.

\section{- Kekerasan}

Analisis data ketebalan paduan kawat baja dilakukan dengan uji One Way Anova dikarenakan sebaran data normal dan varians yang homogen. Nilai yang didapatkan $\mathrm{p}=0.000$ maka dapat disimpulkan bahwa terdapat perbedaan kekasaran antara kelima variasi paduan.

\section{PENUTUP}

\section{Kesimpulan}

Berdasarkan data dan analisa hasil pengujian yang telah dilakukan maka diperoleh kesimpulan sebagai berikut:

1. Penambahan unsur timah (sn) pada paduan $\mathrm{Al}$ $\mathrm{Cu} 10 \%$ dari $10 \%$ sampai $20 \%$ dapat menaikan kekerasan pada lapisan Intermetalik dari $274 \mathrm{~kg} / \mathrm{mm}^{2}$ menjadi $572 \mathrm{~kg} / \mathrm{mm}^{2} \quad$ (Al-Cu10\%-Sn10\%) Selanjutnya menjadi $724 \mathrm{~kg} / \mathrm{mm}^{2}$ (Al-Cu10\%Sn20\%).

2. Penggantian $\mathrm{Cu}$ dengan $\mathrm{Sn}$ pada $(\mathrm{Al}-\mathrm{Cu})$ dapat menaikan kekerasan pada lapisan intermetalik dari $274 \mathrm{~kg} / \mathrm{mm}^{2}$ menjadi $824 \mathrm{~kg} / \mathrm{mm}^{2}$ (Al-Sn10\%).

3. Efek aluminizing dengan menggunakan paduan $\mathrm{Al}$ $\mathrm{Cu}$ atau $\mathrm{Al}-\mathrm{Sn}$ dapat menurunkan kekerasan kawat baja dari $2.756 \mathrm{~kg} / \mathrm{mm}^{2}$ (sampel inisial) menjadi $2.414 \mathrm{~kg} / \mathrm{mm}^{2}$ (Al-Cu10\%-Sn10\%) (Al-Cu10\%Sn20\%).

4. Penambahan unsur timah $(\mathrm{Sn})$ pada paduan $\mathrm{A} 190 \%$ Cu10\% dari $10 \%$ sampai $20 \%$ dapat menurunkan kekerasan pada kawat baja dari $2.450 \mathrm{~kg} / \mathrm{mm}^{2}(\mathrm{Al}-$ $\mathrm{Cu} 10 \%$ ) menjadi $2.430 \mathrm{~kg} / \mathrm{mm}^{2}$ (Al-Cu10\%-Sn10\%) selanjutnya menjadi $2.441 \mathrm{~kg} / \mathrm{mm}^{2}$ (Al-Cu10\%Sn20\%).

5. Penggantian $\mathrm{Cu}$ dengan $\mathrm{Sn}$ dapat menurunkan kekerasan pada kawat baja dari $2.450 \mathrm{~kg} / \mathrm{mm}^{2}(\mathrm{Al}-$ $\mathrm{Cu} 10 \%)$ menjadi $2.414 \mathrm{~kg} / \mathrm{mm}^{2}$ (Al-Sn10\%).

\section{VI.DAFTAR PUSTAKA}

1. Dahlan, M. S. 2009. Uji Hipotesis Komparatif Variabel Numerik $>2$ kelompok. Dalam: Statistik Untuk Kedokteran dan Kesehatan. Salemba Medika, Jakarta. 83-105.

2. Fahran. 2014. Inspeksi Wire Rope Pada Pesawat Angkat. Available from: http:// pusdiklatmigas.esdm.go.id. Diakses pada tanggal 28 November 2016.

3. Kholis, Ikhsan. 2014. Kerusakan craine wire rope dan metode pemeriksanya. Forum teknologi. 4: 5259.

4. Lubis, M. 2010. Steel Wire Rope. Available from: http://repository.usu.ac.id/. Diakses pada tanggal 28 November 2016.

5. Prayitno, D., \& Triyono, M.S. 2010. Pembentukan Lapisan Intermetalik Dengan Metode Powder Liquid Coating Sebagai Upaya Alternatif Pengerasan Permukaan Besi Tuang Nodular. Available from: 
http:// trijurnal.lemlit.trisakti.ac.id. Diakses pada tanggal 28 November 2016.

6. Rajendran, R., et al. 2006. Effect of process parameters in hot dip aluminizing of medium carbon steel. World Automotive Congress. 31 : 1-8.

7. Rey, P, D., \& Prayitno, D. 2015. Pengaruh Aluminizing (Al-Cu) Terhadap laju korosi sambungan las busur rendam tabung gas elpiji $3 \mathrm{Kg}$. Available from: http:// trijurnal.lemlit.trisakti.ac.id. Diakses pada tanggal 15 Juni 2016.

8. Riyono, S. 2014. Wire Rope and Rigging Equipment for Crane Inspector. Available from: http:// jlab.org. Diakses pada tanggal 28 November 2016.

9. Robbina, M, A. 2012. Perbandingan Nilai Kekerasan Dan Struktur Mikro Akibat Variasi Katalis Pada Proses Carburizing Baja S45c. Available from: http://lib.unnes.ac.id/. Diakses pada tanggal 28 November 2016.

10. Sayenga, D. 2014. Sejarah Modern Tali Kawat Baja (Wire Rope). Available from: http://khutauruk.co.id. Diakses pada tanggal 28 November 2016.

11. Shankar, S. 2002. Die Soldering: Mechanism of the Interface Reaction between Molten Aluminum Alloy and Tool Steel. Metallurgical And Materials Transactions B. 33B : 465-476.

12. Sudiashri et al. 2012. Pengaruh Variasi Temperatur Dan Waktu Difusi Hot Dip Alumizing Terhadap Ketahanan Erosi Dan Temperatur Tinggi Pada Material SA 106 Grade B. Jurnal Teknik Pomits. 1: 1-6.

13. Suharno, B., et al. 2007. Morfologi dan karakteristik lapisan intermetalik akibat die soldering pada permukaan baja cetakan (dies) dalam proses pengecoran tekan paduan aluminium silikon. Teknik mesin. 9: 47-53.

14. Widodo, A, H. 2012. Perencanaan Pengangkatan Peralatan Pemboran. Available from: http://digilib.mercubuana.ac.id/. Diakses pada tanggal 28 November 2016.

15. Wijaya, H. A. 2012. Oksidasi Baja Karbon Rendah Aisi 1020 Pada Temperatur $700^{\circ} \mathrm{c}$ Yang Dilapisi Aluminium Dengan Metode Celup Panas (Hot Dipping). Available from: http://digilib.unila.ac.id/. Diakses pada tanggal 28 November 2016.

16. Zaki, A. 2006. Principles of crroin engineering and corrosion control. Elsevier Ltd, Burlington. 